\title{
Psychological morbidity and health-related quality of life after injury: multicentre cohort study
}

\author{
D. Kendrick ${ }^{1}$ (1) B. Kelllezi ${ }^{2}$ C. Coupland ${ }^{1} \cdot$ A. Maula ${ }^{1} \cdot$ K. Beckett $^{3} \cdot$

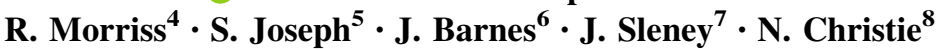

Accepted: 13 October 2016/Published online: 26 October 2016

(c) The Author(s) 2016. This article is published with open access at Springerlink.com

\begin{abstract}
Purpose To demonstrate the impact of psychological morbidity 1 month post-injury on subsequent post-injury quality of life (HRQoL) in a general injury population in the UK to inform development of trauma care and rehabilitation services.

Methods Multicentre cohort study of 16-70-year-olds admitted to 4 UK hospitals following injury. Psychological morbidity and HRQoL (EQ-5D-3L) were measured at recruitment and 1, 2, 4 and 12 months post-injury. A reduction in EQ-5D compared to retrospectively assessed pre-injury levels of at least 0.074 was taken as the minimal
\end{abstract}

Electronic supplementary material The online version of this article (doi:10.1007/s11136-016-1439-7) contains supplementary material, which is available to authorized users.

D. Kendrick

denise.kendrick@nottingham.ac.uk

1 Division of Primary Care, University of Nottingham, University Park, Nottingham NG7 2RD, UK

2 Division of Psychology, Nottingham Trent University, Nottingham NG1 4BU, UK

3 Research and Innovation, University of the West of England, Bristol BS2 8AE, UK

4 Division of Psychiatry and Applied Psychology, University of Nottingham, Nottingham NG7 2TU, UK

5 School of Education, University of Nottingham, Nottingham NG8 1BB, UK

6 Loughborough Design School, Loughborough University, Loughborough LE11 3TU, UK

7 Department of Sociology, University of Surrey, Guildford GU2 7XH, UK

8 Centre for Transport Studies, University College London, London WC1E 6BT, UK important difference (MID). Multilevel logistic regression explored relationships between psychological morbidity 1 month post-injury and MID in HRQoL over the 12 months after injury.

Results A total of 668 adults participated. Follow-up rates were $77 \%$ (1 month) and 63\% (12 months). Substantial reductions in HRQoL were seen; 93\% reported a MID at 1 month and 58\% at 12 months. Problems with pain, mobility and usual activities were commonly reported at each time point. Depression and anxiety scores 1 month post-injury were independently associated with subsequent MID in HRQoL. The relationship between depression and HRQoL was partly explained by anxiety and to a lesser extent by pain and social functioning. The relationship between anxiety and HRQoL was not explained by factors measured in our study.

Conclusions Hospitalised injuries result in substantial reductions in HRQoL up to 12 months later. Depression and anxiety early in the recovery period are independently associated with lower HRQoL. Identifying and managing these problems, ensuring adequate pain control and facilitating social functioning are key elements in improving HRQoL post-injury.

Keywords Unintentional injury - Quality of life . Depression · Anxiety · Cohort study

\section{Introduction}

Injuries are a leading cause of mortality and morbidity. They result each year in 4.8 million deaths worldwide, equivalent to $9 \%$ of all deaths [1]. Globally, there were 656 million injuries in 2013 accounting for 37 million years lived with disability [2]. Injuries are therefore not rare 
events: it has been estimated that $25 \%$ of men and $13 \%$ of women will be exposed to a life-threatening injury in their lifetime [3].

Psychological sequelae are common after injury, particularly post-traumatic stress disorder (PTSD), acute stress disorder, depression and anxiety [4]. The prevalence of PTSD varies across studies, with rates between 17.5 and $42 \%$ at 1-6 months post-injury and between 2 and $36 \%$ at 12 months post-injury [5, 6]. The prevalence of depression between 3 and 18 months after injury is reported as between 6 and 42\% [7-11] and that of anxiety disorders between 4 and 24\% [7-9, 11]. Comorbidity between psychological symptoms is also common postinjury [11]. Whilst studies have reported reductions in quality of life associated with psychological sequelae of injury [4], many have focussed on specific injury types, e.g. burns [12-14], multiple trauma [15] or those admitted to intensive care units $[15,16]$. Several studies have found psychological problems after injury can have a greater impact on quality of life than the physical injury $[4,10,17,18]$ and impairments to quality of life can persist after resolution of the psychological symptoms [19]. Few studies have focussed on the relationship between psychological morbidity and quality of life after injury amongst general injury populations, including those with minor and more major injuries [4, 16, 20, 21]. Identifying and managing psychological problems are recognised as an important component of UK post-injury care for major trauma [22] or for specific injuries such as burns [23], head injuries [24] or spinal cord injuries [25]. However, many injuries admitted to UK hospitals do not fall into these categories, and recent UK research highlights unmet psychological needs [26] and gaps in service provision for such patients [27]. Identification and management of psychological morbidity early in the recovery period have the potential to improve quality of life postinjury [5]. The aim of this study was therefore to demonstrate the impact of psychological morbidity one month post-injury on subsequent quality of life in a general injury population in the UK to inform development of trauma care and rehabilitation services.

\section{Methods}

The methods of the Impact of Injuries Study have been described in detail in the published protocol [28].

\section{Study design}

Prospective longitudinal study set in four NHS hospitals in Nottingham, Bristol, Leicester and Guildford, UK.

\section{Participants}

Consenting participants, aged 16-70 years, were recruited following hospital admission within 3 weeks of unintentional injury between June 2010 and June 2012. Those without an address (due to inability to follow-up) and significant head injury (loss of consciousness, amnesia or a Glasgow coma scale of $<15$ ) were excluded due to difficulty distinguishing between sequelae of head injury and psychological morbidity $[29,30]$. Participants were recruited face to face, by post or by phone. Quota sampling was used between June 2010 and May 2011, but due to slower than expected recruitment, all eligible patients were invited to participate from June 2011.

\section{Data collection}

Participants completed self-administered questionnaires at recruitment and at 1, 2, 4 and 12 months post-injury. Questionnaires at recruitment measured injury details, socio-demographic details including area-level deprivation (the Index of Multiple Deprivation (IMD) 2010) [31]; longterm health conditions and the following pre-injury (i.e. retrospective) measures: quality of life (EQ-5D-3L which comprises five dimensions including mobility, self-care, usual activities, pain, anxiety/depression; each rated as extreme, some or no problem on the day before injury) [32], anxiety and depression (Hospital Anxiety and Depression Scale (HADS) in the week before injury) [33], alcohol problems (Alcohol Use Disorder Identification Test (AUDIT) before the injury) [34], substance use (Drug Abuse Screening Test (DAST) in the 12 months before injury) [35], social functioning (Social Functioning Questionnaire (SFQ) in the 2 weeks before injury) [36] and a $10-\mathrm{cm}$ pain visual analogue scale with "no pain" at $0 \mathrm{~cm}$ and "the worst pain imaginable" at $10 \mathrm{~cm}$ on the day before injury [37]. We used retrospective measurement of pre-injury HRQoL which may be more appropriate than population norms for measuring changes in HRQoL postinjury because injured patients may not be representative of the general population in terms of pre-injury health status $[38,39]$ and retrospectively measured HRQoL more closely matches that of patients fully recovered from injury than does population normative data [38, 39]. The EQ-5D utility index was calculated using the EQ-5D Stata command based on a UK value set [40].

The Abbreviated Injury Scale (AIS) [41] was used to score injury severity using medical record data. Participants' maximum injury severity across all injuries was grouped into three categories minor (AIS $=1$ ), moderate $($ AIS $=2$ ) and serious to maximum (AIS $=3-6$ ). Followup questionnaires also included the Impact of Event Scale (IES) [42], stressful life events related to the injury (List of 
Threatening Events (LTE)) [43], time off work since injury, self-reported recovery [44], social support (Crisis Support Scale (CSS)) [45], changes in outlook (Change in Outlook Questionnaire) [46] and legal proceedings or compensation claims resulting from the injury. Cronbach's alpha coefficients for scales are given in online Table 1.

\section{Statistical analysis}

A statistical analysis plan, detailing the variables considered for inclusion in the models and the process of model building, was written prior to undertaking analyses. Variables were considered for model inclusion based on the literature and theoretical plausibility. Analyses presented are based on 513 participants returning one-month followup questionnaires because psychological, social and legal measures one month post-injury were used as potential predictors of subsequent HRQoL. Participant characteristics are described using frequencies and percentages for categorical data and means (standard deviation (SD)) or medians (interquartile range (IQR)) for continuous data. Characteristics of those returning questionnaires were compared to those not returning 2-, 4- and 12-month questionnaires using Chi-square tests for categorical variables and t-tests or Mann-Whitney $U$ tests for continuous variables.

The primary outcome for analysis was a minimal important difference (MID) or more in the EQ-5D utility index defined as a reduction of at least 0.074 [47] compared with the pre-injury EQ-5D value measured retrospectively at recruitment to the study. This was calculated as a binary variable at 2, 4 and 12 month follow-up. We estimated odds ratios and $95 \%$ CI for the MID in the EQ5D utility index using 2 level random effect logistic regression with observations at level 1 (2, 4, 12 months) and participants at level 2. Linearity of relationships between continuous variables and the MID reduction in EQ-5D was assessed by adding higher-order terms to models, and if these were significant, then the variables were categorised for inclusion in the models (see Tables 2, 3; online Tables 3, 4). Other variables were included as binary, categorical or continuous variables depending on the type of variable (see Tables 2, 3; online Tables 3, 4). Multivariable models were built by entering a priori defined confounders (study centre, age and sex) and time post-injury in one block. Psychological measures at one month (depression, anxiety, IES, AUDIT and DAST) were then added in order of significance on univariate analysis and retained if the likelihood ratio test (LRT) $p$ value was $<0.05$. Other confounding factors measured at recruitment (number of past psychiatric morbidities, psychological measures, long-standing illness, work status, ethnic group, marital status, deprivation, length of hospital stay and injury characteristics) were then added in one block. Variables in this block were removed in order of least statistical significance. Those with a LRT $p$ value of $<0.05$ or whose removal changed odds ratios for one-month psychological measures by $>10 \%$ were retained in the model. Finally other potential confounders measured at one month were added (pain, social functioning, social support, changes in outlook, life events, compensation and litigation) in one block and tested for removal as above. We tested for interactions between one-month psychological measures and time, age and sex in the final model ( $p$ value $<0.01)$. Collinearity was assessed by the covariance correlation matrix and estimating variance inflation factors.

Multiple imputation with chained equations was used to impute missing values for all 668 participants recruited to the study. The imputation model included study centre, age, sex, pre-injury EQ-5D value and EQ-5D values at 1, 2, 4 and 12 months post-injury, and all variables considered in the blocks described above, including those measured at recruitment and at 1, 2, 4 and 12 months post-injury. Fifty imputed datasets were generated, and the imputed values were used to calculate the MID in the EQ-5D utility index scores at 2, 4 and 12 months compared with pre-injury EQ$5 \mathrm{D}$ values as described above. Results of the multiple imputation analyses were combined across the imputed datasets using Rubin's rules [48] first restricted to the participants who completed the 1-month questionnaire and then for all participants recruited to the study.

Stata v13 was used for all analyses [49].

Ethical approval for the study was provided by Nottingham Research Ethics Committee 1 (number: 09/H0407/ 29).

\section{Results}

The flow of participants through the study is shown in Fig. 1. In total, 668 adults were recruited to the study, with $77 \%(n=513)$ followed up at one month and $63 \%$ $(n=421)$ at 12 months. The main analyses presented in this paper are restricted to those returning one-month questionnaires $(n=513)$. Their characteristics are shown in Table 1.

Table 2 online shows characteristics of those returning $(n=328)$ and not returning $(n=185)$ all follow-up questionnaires subsequent to the 1-month questionnaire. Those returning all questionnaires were more likely to be older, female, married, describe their ethnic group as white, live in a more affluent area and be retired. They had lower pre-injury AUDIT and DAST scores and better social functioning. At one month post-injury, they had lower IES intrusion, AUDIT, DAST and pain VAS scores and reported greater social support. 
Table 1 Characteristics of study participants who completed 1-month follow-up questionnaire

\begin{tabular}{ll}
\hline Characteristics & $\begin{array}{l}\text { Number }(\%) \text { unless } \\
\text { otherwise specified } \\
(n=513)\end{array}$
\end{tabular}

Characteristics measured at recruitment

Centre

Nottingham
Loughborough
Bristol
Surrey
Age
$16-24$
$25-44$
$45-64$
$\geq 65$
Sex
Female
Male
Pre-injury EQ-5D
Mean (SD)
Median (IQR)
Pre-injury pain VAS score
Mean (SD)
Median (IQR)

Number of psychiatric diagnoses in past

0

1

$2+$

Pre-injury HADS depression score

Mean (SD)

Median (IQR)

Pre-injury HADS anxiety score

Mean (SD)

Median (IQR)

Pre-injury AUDIT score

Mean (SD)

Median (IQR)

Pre-injury DAST score

Mean (SD)

Median (IQR)

Long-standing illness

No

Yes

Employment

Paid employment

Not working due to illness or disability

Unemployed

193 (37.6)

$129(25.2)$

$150(29.4)$

$41(8.0)$

60 (11.7)

125 (24.4)

256 (49.9)

72 (14.0)

267 (52.1)

246 (48.0)

[6]

$0.92(0.18)$

$1(0.85,1)$

[2]

$5.4(13.3)$

$0(0,2)$

435 (84.8)

$51(9.9)$

27 (5.3)

[2]

$1.5(2.5)$

$0(0,2)$

[2]

$3.0(3.5)$

$2(0,5)$

[14]

4.7 (4.5)

$4(2,6)$

[4]

$0.1(0.5)$

$0(0,0)$

[5]

385 (75.8)

123 (24.2)

[5]

299 (58.9)

25 (4.9)

17 (3.4)

13 (2.6)

111 (21.9)

43 (8.5)
Table 1 continued

Characteristics

Number (\%) unless otherwise specified $(n=513)$

Ethnic group

[2]

White

493 (96.5)

Black or minority ethnic group

18 (3.5)

Deprivation score (IMD)

[12]

Mean (SD)

17.0 (13.4)

Median (IQR)

$12.7(7.2,22.5)$

Marital status

[3]

Single

129 (25.3)

Married/partnership

$296(58.0)$

Divorced/widowed

85 (16.7)

Nights in hospital

[16]

Mean (SD)

$7.3(6.0)$

Median (IQR)

$6(3,10)$

Injury severity

[1]

Minor

25 (4.9)

Moderate

$370(72.3)$

Serious or worse

117 (22.9)

Number of injuries

247 (48.2)

$155(30.2)$

111 (21.6)

$\geq 3$

40 (7.8)

Other

84 (16.4)

Upper limb

338 (65.9)

Upper and lower limbs

$51(9.9)$

Injury mechanism

Other

38 (7.4)

Falls

$341(66.5)$

Traffic

101 (19.7)

Struck

$33(6.4)$

Place of injury

[1]

Other

85 (16.6)

Home

$104(20.3)$

47 (9.2)

$151(29.5)$

Road

$63(12.3)$

Countryside

$62(12.1)$

Characteristics measured at 1 month

HADS depression score

[1]

Mean (SD)

$6.1(4.3)$

Median (IQR)

$5(3,9)$

HADS anxiety score

[1]

Mean (SD)

$5.8(4.4)$

Median (IQR)

$5(2,9)$

AUDIT score

[13]

Mean (SD)
3.4 (4.4) 
Table 1 continued

\begin{tabular}{|c|c|}
\hline Characteristics & $\begin{array}{l}\text { Number }(\%) \text { unless } \\
\text { otherwise specified } \\
(n=513)\end{array}$ \\
\hline Median (IQR) & $2(0,5)$ \\
\hline DAST score & {$[7]$} \\
\hline Mean (SD) & $0.1(0.4)$ \\
\hline Median (IQR) & $0(0,0)$ \\
\hline IES avoidance score & [3] \\
\hline Mean (SD) & $7.8(9.0)$ \\
\hline Median (IQR) & $5(0,12.6)$ \\
\hline IES intrusion score & {$[3]$} \\
\hline Mean (SD) & $8.3(8.9)$ \\
\hline Median (IQR) & $5(1,13)$ \\
\hline SFQ score & {$[5]$} \\
\hline Mean (SD) & $7.5(3.6)$ \\
\hline Median (IQR) & $7(5,9.6)$ \\
\hline CSS score & {$[2]$} \\
\hline Mean (SD) & $32.0(6.1)$ \\
\hline Median (IQR) & $33(28,36)$ \\
\hline CIOP score & [4] \\
\hline Mean (SD) & $19.5(6.5)$ \\
\hline Median (IQR) & $21(16,24)$ \\
\hline CION score & {$[4]$} \\
\hline Mean (SD) & $10.0(5.1)$ \\
\hline Median (IQR) & $9(5,12)$ \\
\hline Life events since injury & {$[14]$} \\
\hline No & $426(85.4)$ \\
\hline Yes & 73 (14.6) \\
\hline Pain VAS score & {$[4]$} \\
\hline Mean (SD) & $30.2(22.6)$ \\
\hline Median (IQR) & $25(12,49)$ \\
\hline Seeking compensation & {$[31]$} \\
\hline No & 385 (79.9) \\
\hline Yes & $97(20.1)$ \\
\hline Involved in litigation & {$[7]$} \\
\hline No & $435(86.0)$ \\
\hline Yes & $71(14.0)$ \\
\hline
\end{tabular}

[ ] missing values. Pre-injury scores measured retrospectively at recruitment to study

HADS Hospital Anxiety and Depression Scale [33], IES Impact of Event Scale [42], AUDIT Alcohol Use Disorder Identification Test [34], DAST Drug Abuse Screening Test [35], VAS visual analogue scale [37], $S F Q$ Social Functioning Questionnaire [36], CSS Crisis Support Scale [45], CIOP Change in Outlook Questionnaire (positive changes [46]), CION Change in Outlook Questionnaire (negative changes [46])

There were substantial reductions from the retrospectively measured pre-injury EQ-5D at all follow-up time points. Mean EQ-5D scores reduced from 0.92 (SD 0.18) pre-injury, to $0.44(0.28)$ at one month, $0.57(0.27)$ at
2 months, $0.69(0.23)$ at 4 months and $0.78(0.21)$ at 12 months. Figure 2 shows EQ-5D utility index scores, changes from pre-injury values and the proportion with a MID reduction over time. The greatest EQ-5D reduction occurred at one month post-injury (median reduction -0.41 , IQR $-0.74,-0.31$ ) and this diminished over time. At 12 months post-injury, three-fifths of participants (62\%, $n=232$ ) still had a lower EQ-5D than before their injury (median reduction -0.15 , IQR $-0.27,0$ ). Virtually all $(n=474,93 \%)$ participants had a MID reduction in EQ5D one month post-injury, with $87 \%(n=367), 77 \%$ $(n=313)$ and $58 \%(n=216)$ still reporting a MID reduction at 2, 4 and 12 months, respectively.

Online Fig. 1 shows the percentage of participants reporting problems on the five dimensions of the EQ-5D over time. The highest prevalence of problems on all dimensions was at 1 and 2 months. For all dimensions, the prevalence of problems remained higher one year after injury than prior to the injury. Problems with pain, mobility and usual activities were the most commonly reported problems at each time point. Some or extreme problems persisted up to one year for a substantial proportion of participants (pain (64\%), mobility (38\%) and usual activities (38\%)).

Online Table 3 shows the proportions with a MID in EQ-5D from pre-injury values, over time, by socio-demographic, injury and psychological measures at recruitment. The number of nights in hospital post-injury, greater injury severity, multiple injuries, lower limb or both upper and lower limb injuries and injuries occurring at work were associated with a higher odds of a MID in EQ-5D. Those with pre-existing long-standing illness, unemployed due to illness or disability, recruited from Surrey or with penetrating injuries had a lower odds of a MID in EQ-5D.

Psychological problems were common in the early recovery period. One month post-injury $15 \%(n=78)$ met the case definition (HADS depression subscale score $\geq 11$ ) for depression, and 19\% ( $n=97)$ were classified as borderline depressed (HADS depression subscale score 8-10). For anxiety, $16 \%(n=82)$ met the case definition (HADS anxiety subscale score $\geq 11)$ and $15 \%(n=78)$ were classified as borderline for anxiety (HADS anxiety subscale score 8-10). Online Table 4 shows the proportions with a MID in EQ-5D from pre-injury values, over time, by pain, psychological, social and legal factors measured at one month post-injury. Higher pain, depression, anxiety and impact of events scale scores were associated with a higher odds of a MID in EQ-5D. Poorer social functioning, greater positive changes in outlook, greater negative changes in outlook, seeking compensation or being involved in litigation were also associated with a higher odds of a MID in EQ-5D. Higher levels of social support were associated with a lower odds of a MID in EQ-5D. 
Table 2 shows the results of the multivariable analysis. Across all models (B-E), participants with higher depression scores at one month post-injury were more likely to experience a MID reduction in EQ-5D than those with lower scores. Adding anxiety to the model (model C) resulted in substantial reductions in the odds ratios for depression. Adding pain, social and legal factors to the model (model E) further reduced the odds ratios for depression (to a lesser extent than when adding anxiety), but depression remained significantly associated with a MID reduction in EQ-5D in the final model.

Across all models ( $\mathrm{C}$ to $\mathrm{E}$ and final model), participants with higher anxiety scores one month post-injury were significantly more likely to experience a MID reduction in EQ-5D than those with lower scores. The relationship between anxiety and EQ-5D did not appear to be explained by demographic, injury, pre-injury psychological measures, pain, social or legal factors. Other psychological measures one month post-injury (IES, AUDIT, DAST) were not significantly associated with EQ-5D, once depression and anxiety were included in the models.

Several other factors were independently associated with increased odds of a MID reduction in EQ-5D. This included increasing age and increasing injury severity. Those with upper limb or lower limb injuries had greater odds of a MID reduction in EQ-5D than those with other injuries; as did those with two injuries compared to those with one injury. Each extra night in hospital increased the odds of a MID reduction in EQ-5D by $8 \%$. Those with higher pain scores and those with poorer social functioning had increased odds of a MID reduction in EQ-5D. There were no significant interactions between depression or anxiety scores and time, age or sex in the final model. This suggests the impact of symptoms of depression and anxiety one month after injury on HRQoL was similar at over time and did not vary by age or sex.

Pre-injury depression score, long-standing illness, being unemployed due to illness or disability and being recruited in Bristol or Surrey were independently associated with a reduced odds of a MID reduction in EQ5D. Online Fig. 2 shows pre-injury EQ-5D was significantly lower for those with long-standing illness, unemployed due to illness or disability and with higher depression scores, suggesting a floor effect may partly explain these findings. Pre-injury EQ-5D was lowest in Bristol and highest in Surrey; hence, floor effects are unlikely to explain these findings.

Table 3 shows the results of the multivariable analyses for the final model using multiply imputed data. The results using multiply imputed data were similar for the analyses of one month responders and of all participants recruited to the study, but there were some differences when compared with the final model results in Table 2; in particular, the odds ratios for the quintiles of HADS depression score were lower and no longer statistically significant.

The highest variance inflation factors (VIFs) were for the dummy variables for body part injured (upper limb (2.90), lower limb (3.62), upper and lower limb (2.56)) which had a small number of participants in the reference group (see Table 1-other site of injuries). Of note, all other VIF values were below 2.50, including depression score pre-injury (1.43) and at one month (2.42), anxiety score at one month (2.39), social functioning score at one month (2.11), pain visual analogue scale at one month (1.29), number of psychiatric morbidities at recruitment (1.16) and long-standing illness at recruitment (1.32).

\section{Discussion}

\section{Main findings}

Injuries requiring hospitalisation result in substantial and clinically important reductions in HRQoL up to 12 months later. Depression and anxiety were common one month post-injury, and higher scores were independently associated with clinically important reductions in HRQoL between 2 and 12 months post-injury. The relationship between depression score and HRQoL was partly explained by anxiety score and to a lesser extent by pain and social functioning. The relationship between anxiety score and HRQoL was not explained by any of the factors measured in our study. The impact of symptoms of depression and anxiety one month after injury on HRQoL appeared similar at 2, 4 and 12 months post-injury.

\section{Strengths and limitations}

This is the first prospective multicentre UK study to report relationships between early psychological morbidity and subsequent quality of life in working age adults admitted to hospital for a wide range of injuries. Participants were followed up for 1 year post-injury, but previous studies show, at best, only small improvements in HRQoL 9-24 months after injury [50]. Longer-term studies of major trauma patients show HRQoL remains below that for non-injured populations for 6-9 years [51] post-injury. Consequently our 12-month outcomes are likely to reflect longer-term outcomes. Thirty per cent of eligible patients who were invited to join the study participated, and some selection bias may have occurred if those choosing to participate had higher or lower pre-injury HRQoL than those not participating. Follow-up rates were higher than or comparable to similar studies [16, 50, 52-55] but lower than opt-out registry-based cohort studies [56]. There was evidence of some response bias (online Table 2); in 


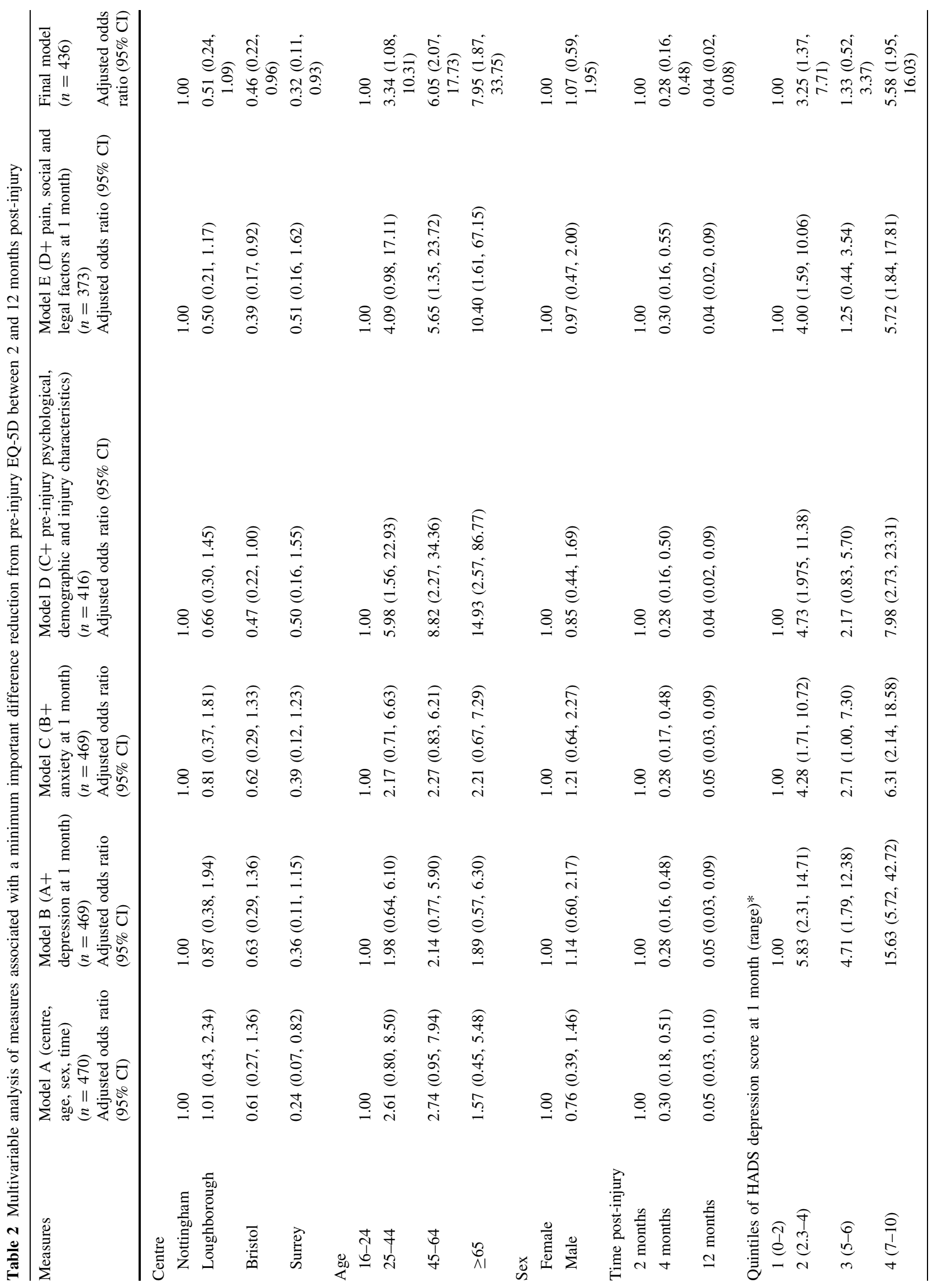




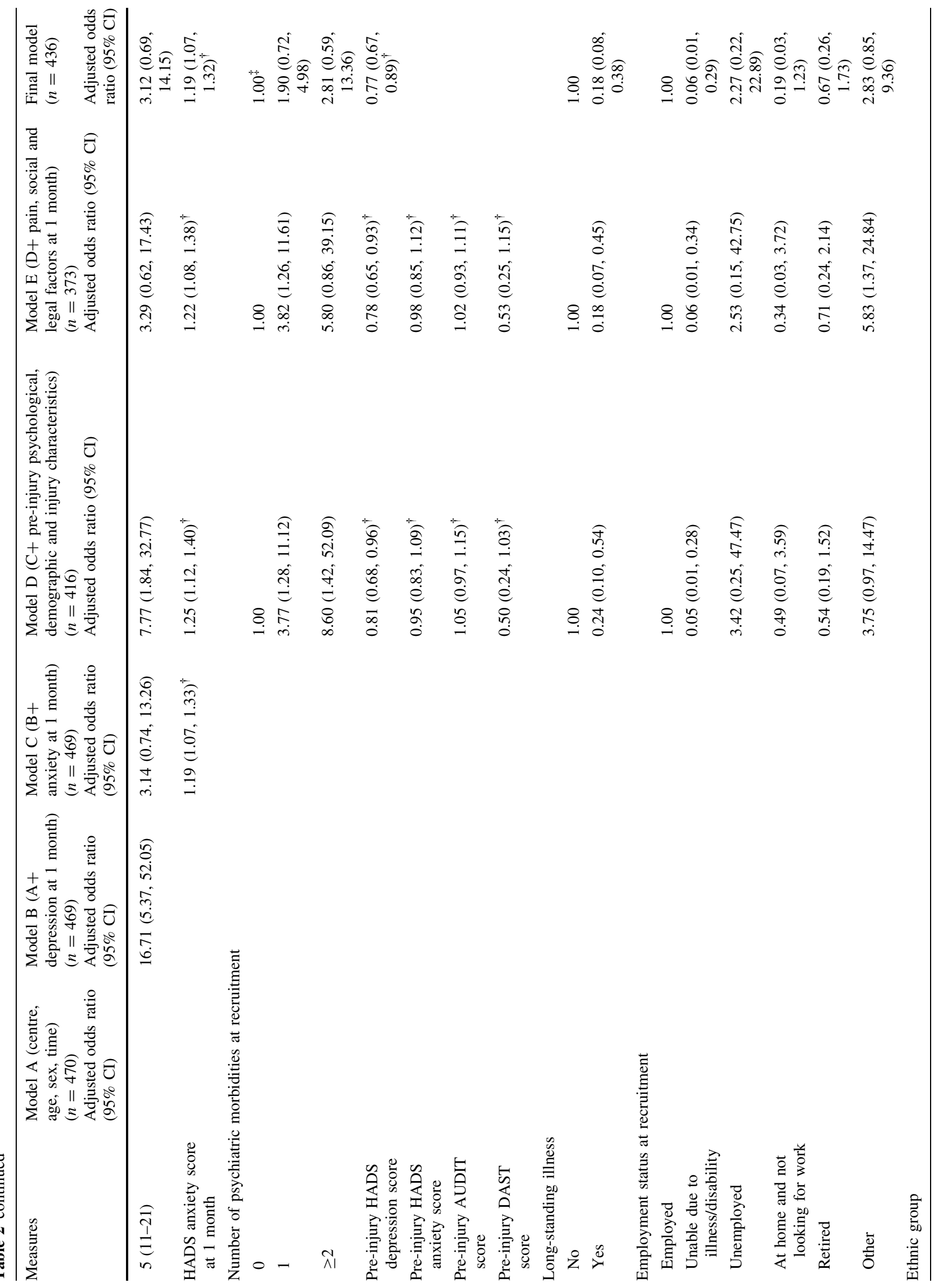




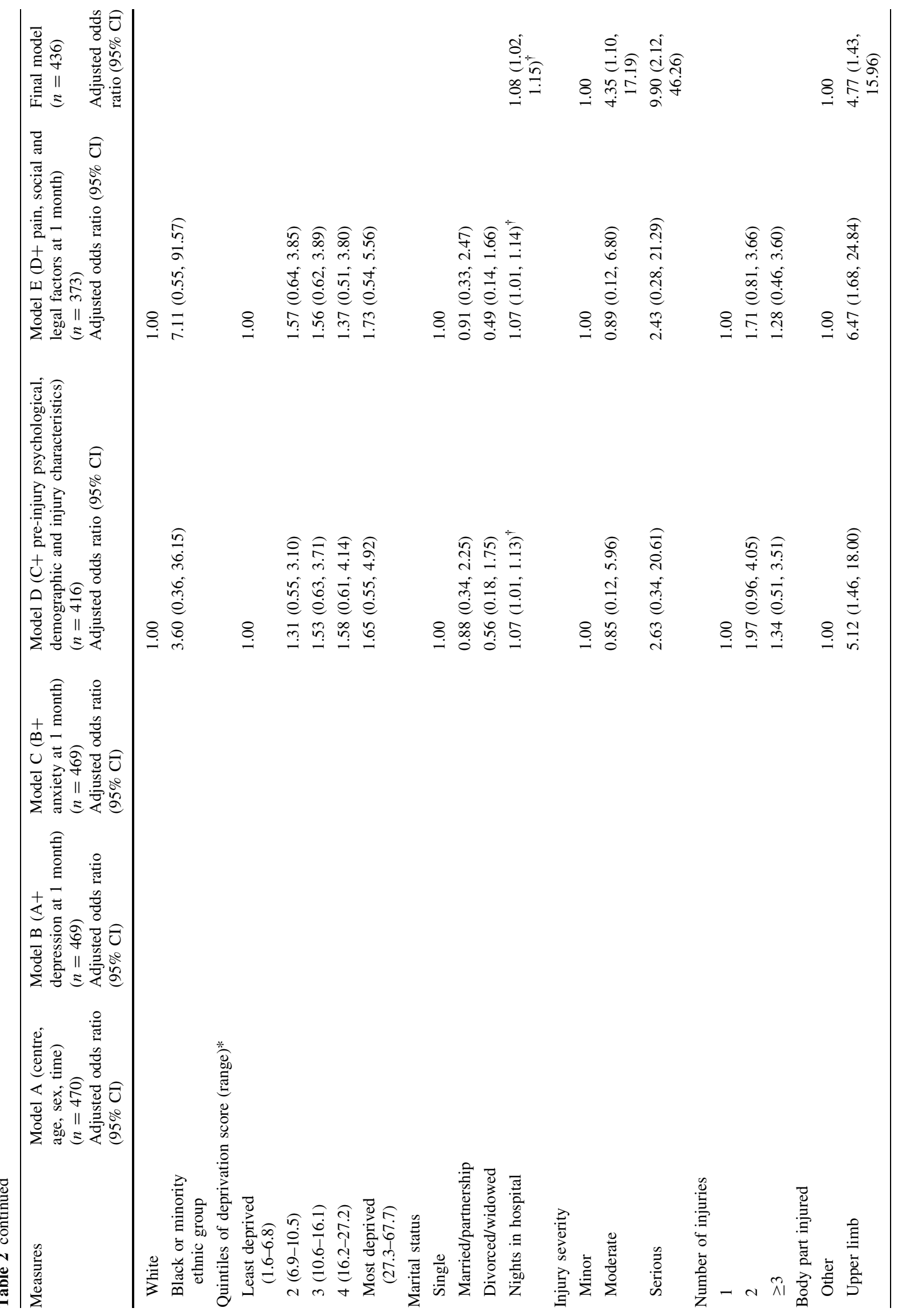




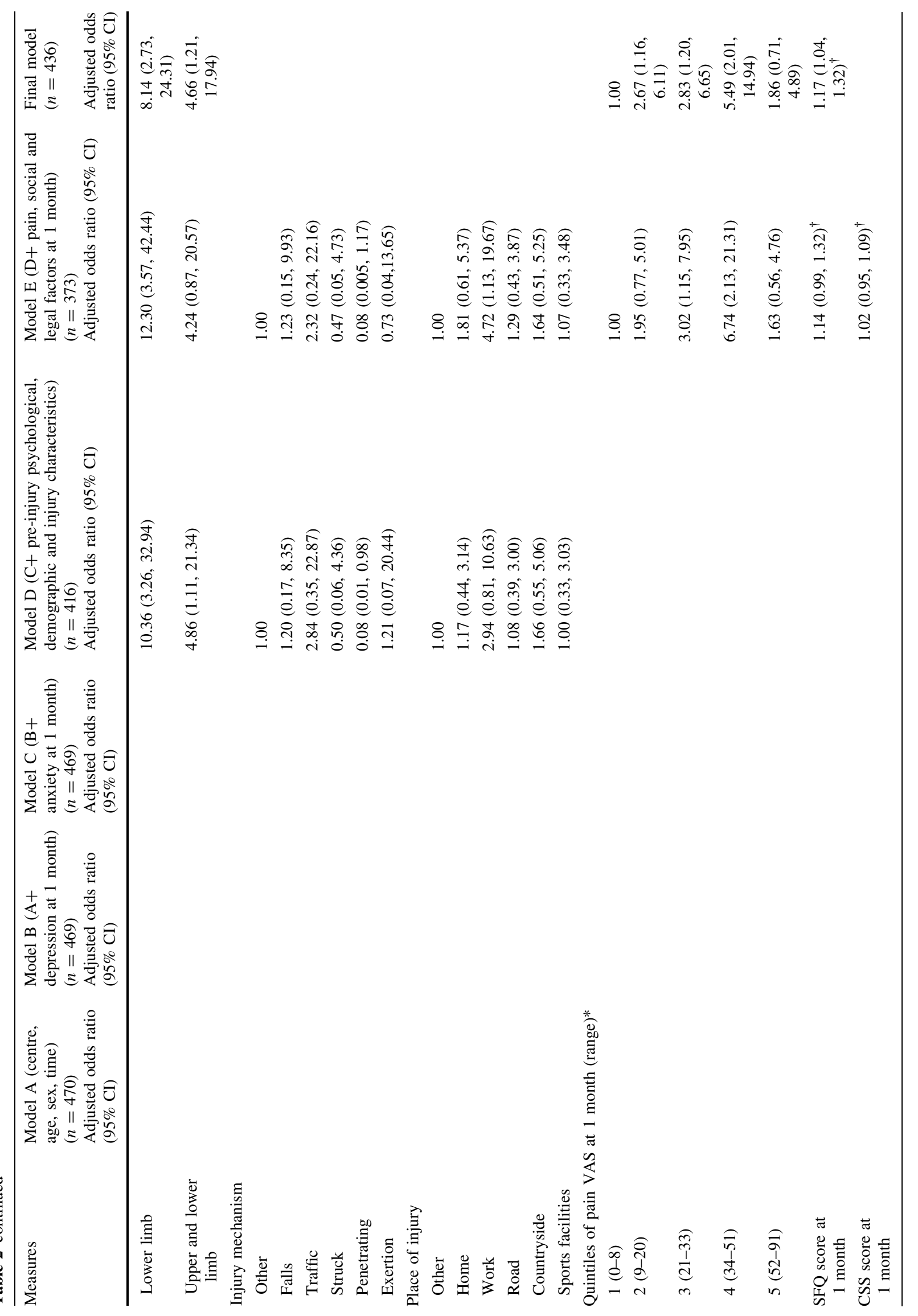




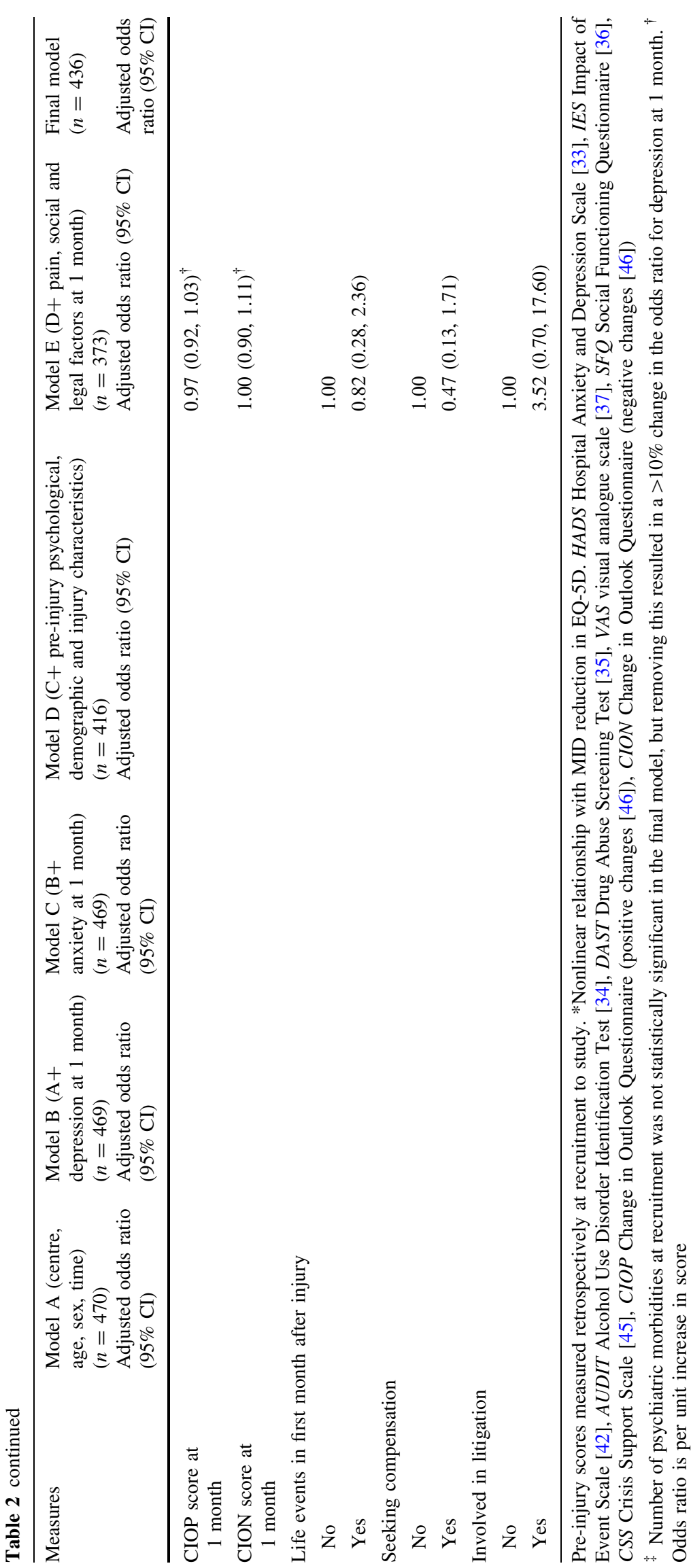


Table 3 Multivariable analysis of measures associated with a minimum important difference reduction from pre-injury EQ-5D at 2, 4 and 12 months post-injury using multiply imputed data

\begin{tabular}{|c|c|c|}
\hline Measures & $\begin{array}{l}\text { Final model in } 1 \text {-month responders }(n=513) \\
\text { Adjusted odds ratio }(95 \% \mathrm{CI})\end{array}$ & $\begin{array}{l}\text { Final model in all participants recruited } \\
\text { to the study }(n=668) \\
\text { Adjusted odds ratio }(95 \% \mathrm{CI})\end{array}$ \\
\hline \multicolumn{3}{|l|}{ Centre } \\
\hline Nottingham & 1.00 & 1.00 \\
\hline Loughborough & $0.62(0.33-1.19)$ & $0.71(0.40-1.28)$ \\
\hline Bristol & $0.53(0.29-0.99)$ & $0.59(0.32-1.06)$ \\
\hline Surrey & $0.43(0.17-1.08)$ & $0.43(0.18-1.06)$ \\
\hline \multicolumn{3}{|l|}{ Age } \\
\hline $16-24$ & 1.00 & 1.00 \\
\hline $25-44$ & $2.40(0.98-5.87)$ & $1.71(0.77-3.78)$ \\
\hline $45-64$ & $3.12(1.36-7.19)$ & $2.17(1.03-4.58)$ \\
\hline$\geq 65$ & $3.28(1.02-10.56)$ & $2.33(0.80-6.78)$ \\
\hline \multicolumn{3}{|l|}{ Sex } \\
\hline Female & 1.00 & 1.00 \\
\hline Male & $1.00(0.60-1.67)$ & $1.07(0.68-1.68)$ \\
\hline \multicolumn{3}{|l|}{ Time post-injury } \\
\hline 2 months & 1.00 & 1.00 \\
\hline 4 months & $0.33(0.20-0.55)$ & $0.42(0.24-0.73)$ \\
\hline 12 months & $0.09(0.05-0.17)$ & $0.14(0.08-0.25)$ \\
\hline \multicolumn{3}{|c|}{ Quintiles of HADS depression score at 1 month (range)* } \\
\hline $1(0-2)$ & 1.00 & 1.00 \\
\hline $2(2.3-4)$ & $1.80(0.87-3.74)$ & $1.66(0.86-3.21)$ \\
\hline $3(5-6)$ & $0.93(0.43-2.00)$ & $1.10(0.54-2.26)$ \\
\hline $4(7-10)$ & $1.83(0.79-4.23)$ & $1.84(0.82-4.15)$ \\
\hline $5(11-21)$ & $1.62(0.48-5.51)$ & $1.83(0.59-5.69)$ \\
\hline HADS anxiety score at 1 month & $1.14(1.04-1.24)^{\dagger}$ & $1.09(1.01-1.18)^{\dagger}$ \\
\hline \multicolumn{3}{|c|}{ Number of psychiatric morbidities at recruitment } \\
\hline 0 & 1.00 & 1.00 \\
\hline 1 & $1.26(0.56-2.82)$ & $1.15(0.57-2.35)$ \\
\hline$\geq 2$ & $2.09(0.60-7.25)$ & $2.10(0.72-6.17)$ \\
\hline Pre-injury HADS depression score & $0.80(0.71-0.90)^{\dagger}$ & $0.81(0.73-0.90)^{\dagger}$ \\
\hline \multicolumn{3}{|l|}{ Long-standing illness } \\
\hline No & 1.00 & 1.00 \\
\hline Yes & $0.23(0.13-0.43)$ & $0.27(0.15-0.46)$ \\
\hline \multicolumn{3}{|l|}{ Employment status at recruitment } \\
\hline Employed & 1.00 & 1.00 \\
\hline Unemployed/unable to work & $0.32(0.14-0.74)$ & $0.38(0.17-0.83)$ \\
\hline Retired & $0.81(0.37-1.77)$ & $0.83(0.41-1.68)$ \\
\hline Other & $1.68(0.60-4.71)$ & $1.40(0.58-3.41)$ \\
\hline Nights in hospital & $1.05(1.00-1.10)^{\dagger}$ & $1.04(1.00-1.09)^{\dagger}$ \\
\hline \multicolumn{3}{|l|}{ Injury severity } \\
\hline Minor & 1.00 & 1.00 \\
\hline Moderate & $2.64(0.92-7.55)$ & $1.91(0.75-4.85)$ \\
\hline Serious & $4.35(1.33-14.22)$ & $2.51(0.89-7.08)$ \\
\hline \multicolumn{3}{|l|}{ Body part injured } \\
\hline Other & 1.00 & 1.00 \\
\hline Upper limb & $2.49(0.93-6.69)$ & $2.39(0.99-5.77)$ \\
\hline Lower limb & $4.60(1.89-11.21)$ & $3.76(1.79-7.91)$ \\
\hline
\end{tabular}


Table 3 continued

\begin{tabular}{lll}
\hline Measures & $\begin{array}{l}\text { Final model in 1-month responders }(n=513) \\
\text { Adjusted odds ratio (95\% CI) }\end{array}$ & $\begin{array}{l}\text { Final model in all participants recruited } \\
\text { to the study }(n=668) \\
\text { Adjusted odds ratio }(95 \% \text { CI })\end{array}$ \\
\hline $\begin{array}{l}\text { Upper and lower limb } \\
\text { Quintiles of pain VAS at 1 month (range)* }\end{array}$ & $3.50(1.12-10.93)$ & $2.99(1.14-7.86)$ \\
$1(0-8)$ & 1.00 & 1.00 \\
$2(9-20)$ & $2.00(0.99-4.06)$ & $1.88(1.00-3.54)$ \\
$3(21-33)$ & $2.01(0.97-4.14)$ & $1.92(0.98-3.77)$ \\
$4(34-51)$ & $2.97(1.30-6.81)$ & $2.75(1.25-6.03)$ \\
$5(52-91)$ & $2.12(0.93-4.85)$ & $2.09(0.98-4.45)$ \\
SFQ score at 1 month & $1.18(1.06-1.30)^{\dagger}$ & $1.14(1.04-1.25)^{\dagger}$ \\
\hline
\end{tabular}

Pre-injury scores measured retrospectively at recruitment to study

* Nonlinear relationship with MID reduction in EQ-5D

$H A D S$ Hospital Anxiety and Depression Scale [33], VAS visual analogue scale [37], SFQ Social Functioning Questionnaire [36]

${ }^{\dagger}$ Odds ratio is per unit increase in score

* Recategorised from complete case analysis as multiple imputation analysis would not run with a larger number of categories

particular, young, single males were less likely to return follow-up questionnaires as were those reporting more problems with alcohol and drugs, higher pain scores, poorer social functioning and less social support. The multiple imputation analysis found the depression score one month post-injury was no longer significantly associated with subsequent HRQoL, possibly because some of the factors associated with non-response (e.g. pain, social functioning) were associated with both depression scores and HRQoL. Taking account of missing data had little impact on the findings relating to anxiety score at one month post-injury.

Previous studies show retrospectively reported pre-injury HRQoL amongst injured populations is likely to show a small upward bias $[38,39,52]$, for a variety of reasons $[38,39,52,57]$. It is possible that some of the reduction in EQ-5D in our study arose from overestimation of pre-injury EQ-5D. However, most participants experienced large reductions in EQ-5D (Fig. 2), so this is unlikely to have had a major impact on our findings. We used the mean MID estimated by Walters and Brazier [47] as the MID for our study. This was estimated using a general health question from the SF-36 as the anchor and repeated measurements of EQ-5D across 11 studies with varied clinical study populations. As we used retrospective assessment of pre-injury EQ-5D and none of the 11 studies included patients hospitalised with a wide range of injuries, it is important to bear this in mind when interpreting our findings. A further limitation is that our sample size for the main analyses was relatively small, and some of our negative findings may be explained by small numbers (e.g. black or minority ethnic group participants, multiple psychiatric morbidities at recruitment, drug problems).
Alternative variable selection methods (e.g. lasso) and validation studies could be used to confirm the robustness of reported results.

\section{Comparisons with existing research}

A recent review of studies [58] measuring the population burden of injuries found few used the EQ-5D [59-62] and only one in a general injury population reported utility scores with which we can compare our findings [50]. Polinder et al. [50] reported EQ-5D utility scores similar to ours amongst admitted adults at 2.5, 5 and 9 months postinjury. This study did not measure psychological morbidity, but found being female, older, having 1 or 2 comorbidities at study recruitment, and spinal cord/vertebral injuries, hip, lower limb or upper limb fractures were associated with poorer HRQoL at 9 and/or at 24 months. These are consistent with our findings in terms of age and limb injuries, but we were unable to explore variations in HRQoL for more specific types of injuries due to small numbers. We found long-standing illness was associated with a lower odds of a MID in EQ-5D, possibly related to floor effects due to lower pre-injury EQ-5D scores. We found no significant association between sex and HRQoL, which may reflect our adjustment for a wider range of confounding factors or our use of the MID in EQ-5D rather than the EQ-5D utility score.

Two more recent studies [38, 63] report EQ-5D utility scores in general injury populations, but neither report factors associated with HRQoL. The UK Burden of Injury study (UKBOI) recruited older children (aged at least 5 years) and adults with predominantly unintentional injury; $44 \%$ of whom were admitted to hospital. They 
Fig. 1 Recruitment and followup of study participants

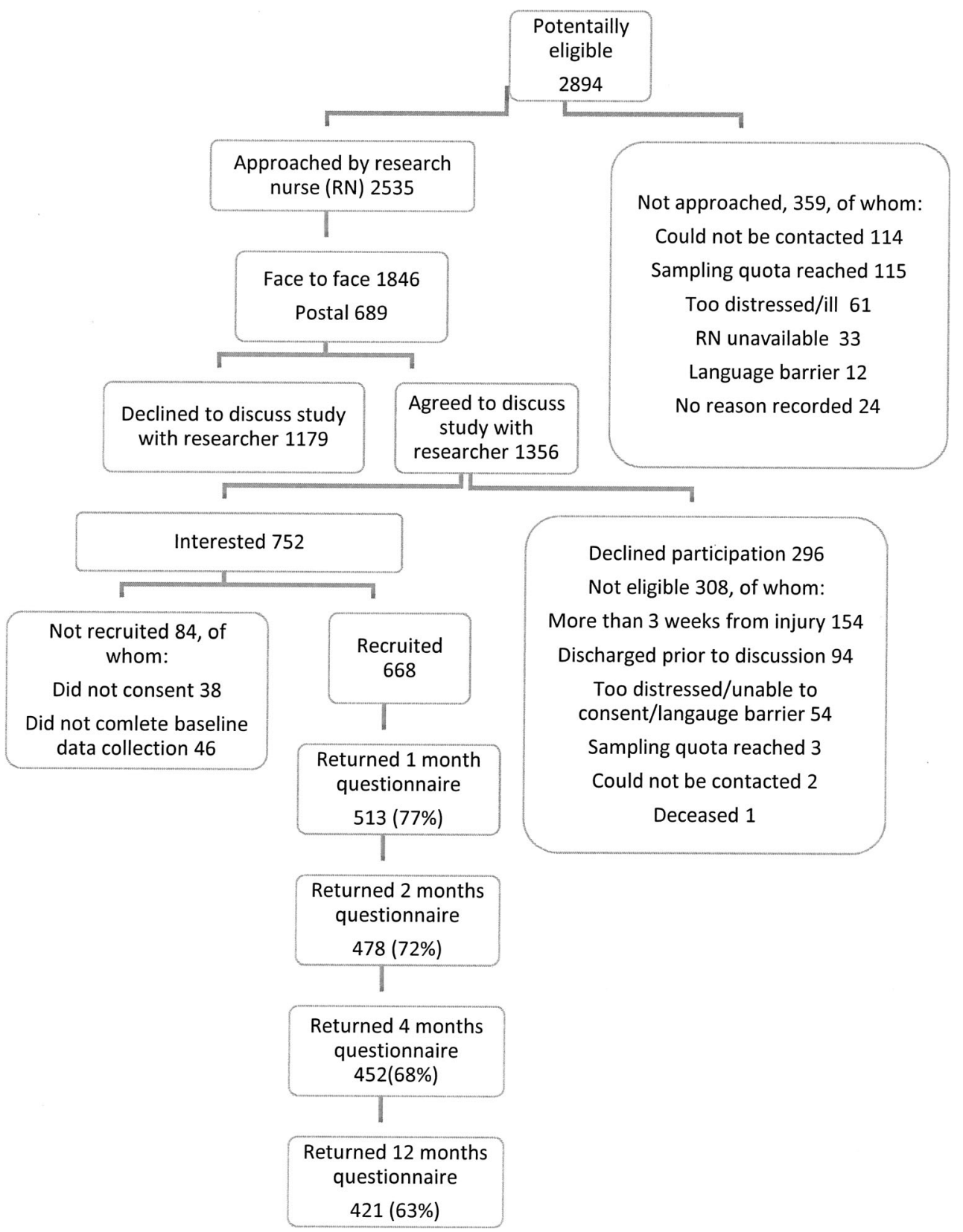

reported higher EQ-5D utility scores at one month (mean 0.61 ), but similar scores at 4 and 12 months to our study. The one-month scores may reflect the inclusion of a younger age group or of ED attenders in the UKBOI [63]. The New Zealand Prospective Outcomes of Injury Study (POIS) recruited unintentionally injured adults aged 18-64 years from an accident compensation register, of whom $25 \%$ were hospitalised, and found similar reductions in EQ-5D utility scores to ours, over a 1-year follow-up period [38]. They also found $18 \%$ of hospitalised patients attained, but did not maintain, their pre-injury HRQoL, and that for hospitalised and non-hospitalised patients combined, the domains most commonly attained but not maintained were those for pain/discomfort $(22 \%)$ and for anxiety/depression (20\%) [64]. This highlights the clinical importance of identifying psychological morbidity in the later phases of recovery, including amongst those previously thought to have recovered.

A 2009 review of psychiatric morbidity, functional impairments and HRQoL following traumatic injuries found depressive and PTSD symptoms, injury type and severity, pre-injury physical functioning and perceived social support predicted HRQoL post-injury [4]. This is consistent with our findings regarding depressive 
Fig. 2 EQ-5D utility index, change from pre-injury values and minimally important difference in EQ-5D at 1, 2, 4 and 12 months post-injury
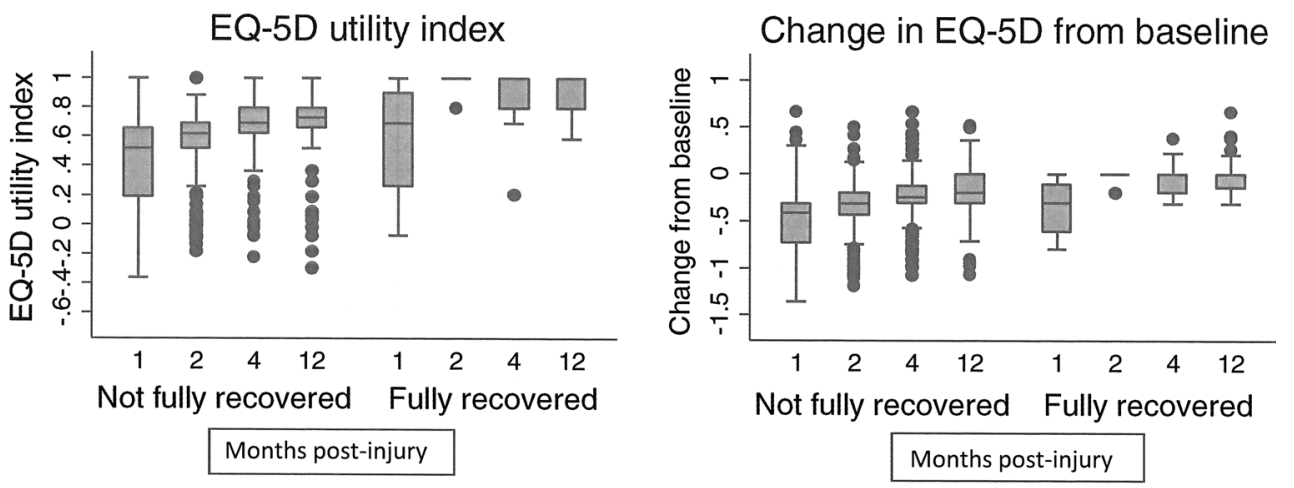

Months post-injury

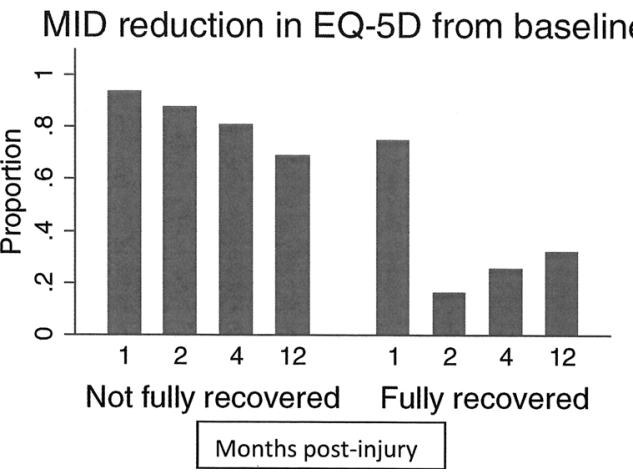

symptoms, pre-existing long-standing illness, injury type and severity. We did not find post-traumatic distress symptoms were associated with HRQoL once depression and anxiety were included in regression models. Comorbidity between depression, anxiety and PTSD is common [11]. In our study, $81 \%$ of those with moderate or severe post-traumatic distress symptoms met the borderline or case criteria for depression and/or anxiety and only $8 \%$ of those not meeting these criteria had moderate or severe post-traumatic distress symptoms (online Table 5; online Fig. 3). This is likely to explain our lack of an association between IES scores and HRQoL in our study.

Other recent studies measuring the impact of psychological morbidity on HRQoL using tools other than the EQ5D report findings consistent with ours. A US study of injured adult ED attenders reported a significantly lower QoL (Quality of Life Index) in those with, than in those without, depression in the 12 months post-injury [21]. Injured adults admitted to a trauma centre in Norway with higher depression scores between 1 and 2 months postinjury had lower HRQoL (SF-36) 12 months post-injury [16]. A small study of major trauma patients in Sweden found large reductions in QoL (SF-36) early post-injury, mainly arising from physical SF-36 dimensions, and normalising within 2 years. This contrasted with persisting reductions in QoL from psychological dimensions [20], consistent with our findings that depression and anxiety predict HRQoL up to 12 months post-injury.

\section{Implications for clinical practice and research}

Depression and anxiety early in the recovery process are common amongst adults admitted to hospital in the UK with a wide range of injuries. Trauma and rehabilitation services and primary care teams have an important role to play in identifying and managing depression and anxiety, controlling pain and helping patients maximise social functioning. Standardised tools exist to identify psychological morbidity post-injury, and there are effective interventions that can be offered to patients $[65,66]$. The challenge for health care providers is to recognise the importance of psychological morbidity post-injury, to implement evidence-based care in day-day practice and for commissioners to ensure availability of effective interventions. Future injury outcome studies should include measures of psychological morbidity and follow-up participants regardless of recovery status at earlier time points. Our findings also illustrate the importance of future studies exploring response bias and undertaking analyses which take account of missing data.

Funding The project was funded by the National Institute for Health Research funding scheme for the Collaboration for Leadership in Applied Health Research and Care Nottinghamshire, Derbyshire and Lincolnshire, and now East Midlands. The views expressed in this work are those of the authors and not necessarily those of the NHS, the NIHR or the Department of Health. The study sponsor had no role in study design, collection, analysis and interpretation of data, the 
writing of the manuscript or the decision to submit the manuscript for publication.

\section{Compliance with ethical standards}

Conflict of interest The authors declare that they have no conflict of interest.

Open Access This article is distributed under the terms of the Creative Commons Attribution 4.0 International License (http://crea tivecommons.org/licenses/by/4.0/), which permits unrestricted use, distribution, and reproduction in any medium, provided you give appropriate credit to the original author(s) and the source, provide a link to the Creative Commons license, and indicate if changes were made.

\section{References}

1. GBD 2013 Mortality and Causes of Death Collaborators. (2015). Global, regional, and national age-sex specific all-cause and cause-specific mortality for 240 causes of death, 1990-2013: A systematic analysis for the Global Burden of Disease Study 2013. The Lancet, 385(9963), 117-171. doi:10.1016/S0140-6736(14) 61682-2.

2. Global Burden of Disease Study. (2013). Collaborators Global, regional, and national incidence, prevalence, and years lived with disability for 301 acute and chronic diseases and injuries in 188 countries, 1990-2013: A systematic analysis for the Global Burden of Disease Study 2013. The Lancet,. doi:10.1016/S01406736(15)60692-4.

3. Kessler, R. C., Sonnega, A., Bromet, E., Hughes, M., \& Nelson, C. B. (1995). Posttraumatic stress disorder in the National Comorbidity Survey. Archives of General Psychiatry, 52(12), 1048-1060. doi:10.1001/archpsyc.1995.03950240066012.

4. Davydow, D. S., Katon, W. J., \& Zatzick, D. F. (2009). Psychiatric morbidity and functional impairments in survivors of burns, traumatic injuries, and ICU stays for other critical illnesses: A review of the literature. International Review of Psychiatry (Abingdon, England), 21(6), 531-538. doi:10.3109/095402609 03343877

5. O'Donnell, M. L., Bryant, R. A., Creamer, M., \& Carty, J. (2008). Mental health following traumatic injury: Toward a health system model of early psychological intervention. Clinical Psychology Review, 28(3), 387-406. doi:10.1016/j.cpr.2007.07.008.

6. O’Donnell, M. L., Creamer, M., Bryant, R. A., Schnyder, U., \& Shalev, A. (2003). Posttraumatic disorders following injury: An empirical and methodological review. Clinical Psychology Review, 23(4), 587-603. doi:10.1016/S0272-7358(03)00036-9.

7. Blanchard, E. B., Hickling, E. J., Freidenberg, B. M., Malta, L. S., Kuhn, E., \& Sykes, M. A. (2004). Two studies of psychiatric morbidity among motor vehicle accident survivors 1 year after the crash. Behaviour Research and Therapy, 42(5), 569-583. doi:10.1016/S0005-7967(03)00162-1.

8. Mason, S., Wardrope, J., Turpin, G., \& Rowlands, A. (2002). The psychological burden of injury: An 18 month prospective cohort study. Emergency Medicine Journal, 19(5), 400-404.

9. Mayou, R., Bryant, B., \& Ehlers, A. (2001). Prediction of psychological outcomes one year after a motor vehicle accident. The American Journal of Psychiatry, 158(8), 1231-1238.

10. Michaels, A. J., Michaels, C. E., Smith, J. S., Moon, C. H., Peterson, C., \& Long, W. B. (2000). Outcome from injury: general health, work status and satisfaction 12 months after trauma. The Journal of Trauma, 48(5), 841-850.
11. O’Donnell, M. L., Creamer, M., \& Pattison, P. (2004). Posttraumatic stress disorder and depression following trauma: Understanding comorbidity. American Journal of Psychiatry, 161(8), 1390-1396. doi:10.1176/appi.ajp.161.8.1390.

12. Dyster-Aas, J., Kildal, M., \& Willebrand, M. (2007). Return to work and health-related quality of life after burn injury. Journal of Rehabilitation Medicine, 39(1), 49-55.

13. Esselman, P. C., Thombs, B. D., Magyar-Russell, G., \& Fauerbach, J. A. (2006). Burn rehabilitation: State of the science. American Journal of Physical Medicine and Rehabilitation, 85(4), 383-413. doi:10.1097/01.phm.0000202095.51037.a3.

14. Pope, S. J., Solomons, W. R., Done, D. J., Cohn, N., \& Possamai, A. M. (2007). Body image, mood and quality of life in young burn survivors. Burns: Journal of the International Society for Burn Injuries, 33(6), 747-755. doi:10.1016/j.burns.2006.10.387.

15. Dimopoulou, I., Anthi, A., Mastora, Z., Theodorakopoulou, M., Konstandinidis, A., Evangelou, E., et al. (2004). Health-related quality of life and disability in survivors of multiple trauma one year after intensive care unit discharge. American Journal of Physical Medicine and Rehabilitation, 83(3), 171-176.

16. Tøien, K., Bredal, I. S., Skogstad, L., Myhren, H., \& Ekeberg, Ø. (2011). Health related quality of life in trauma patients. Data from a one-year follow up study compared with the general population. Scandinavian Journal of Trauma, Resuscitation and Emergency Medicine, 19, 22-23. doi:10.1186/1757-7241-19-22.

17. Zatzick, D. F., Jurkovich, G. J., Gentilello, L., Wisner, D., \& Rivara, F. P. (2002). Posttraumatic stress, problem drinking, and functional outcomes after injury. Archives of Surgery, 137(2), 200-205. doi:10.1001/archsurg.137.2.200.

18. O’Donnell, M. L., Creamer, M., Elliott, P., Atkin, C., \& Kossman, T. (2005). Determinants of quality of life and role-related disability after injury: Impact of acute Psychological Responses. Journal of Trauma: Injury, Infection and Critical Care, 59(6), 1328-1334.

19. Bryant, R. A., McFarlane, A. C., Silove, D., O’Donnell, M. L., Forbes, D., \& Creamer, M. (2015). The lingering impact of resolved PTSD on subsequent functioning. Clinical Psychological Science. doi:10.1177/2167702615598756.

20. Orwelius, L., Bergkvist, M., Nordlund, A., Simonsson, E., Nordlund, P., Bäckman, C., et al. (2012). Physical effects of trauma and the psychological consequences of preexisting diseases account for a significant portion of the health-related quality of life patterns of former trauma patients. Journal of Trauma and Acute Care Surgery, 72(2), 504-512.

21. Richmond, T. S., Guo, W., Ackerson, T., Hollander, J., Gracias, V., Robinson, K., et al. (2014). The effect of postinjury depression on quality of life following minor injury. Journal of Nursing Scholarship, 46(2), 116-124. doi:10.1111/jnu.12064.

22. British Society of Rehabilitation Medicine. Specialist Rehabilitation in the Trauma pathway: BSRM core standards. Version 1.4. (2013). http://www.bsrm.org.uk/downloads/bsrm-core-stan dards-for-major-trauma-24-10-13-version1.4newlogo-forpublica tion-finalforweb-checked1-12-14.pdf. Accessed 11/5/16.

23. National Network for Burn Care. National Burn Care Standards. http://www.britishburnassociation.org/downloads/National_Burn_ Care_Standards_2013.pdf. Accessed 11/5/16.

24. National Institute for Health and Care Excellence. Head injury Quality standard. (2014). https://www.nice.org.uk/guidance/qs74. Accessed 11/5/16.

25. NHS England. NHS standard contract for spinal cord injuries (all ages). Service specification. D13/S/a. (2013). https://www.eng land.nhs.uk/commissioning/wp-content/uploads/sites/12/2014/0 4/d13-spinal-cord-0414.pdf. Accessed 11/5/16.

26. Christie, N., Beckett, K., Earthy, S., Kellezi, B., Sleney, J., Barnes, J., et al. (2016). Seeking support after hospitalisation for injury: A nested qualitative study of the role of primary care. 
British Journal of General Practice, 66(642), e24-e31. doi:10. 3399/bjgp15X688141.

27. Beckett, K., Earthy, S., Sleney, J., Barnes, J., Kellezi, B., Barker, M., et al. (2014). Providing effective trauma care: The potential for service provider views to enhance the quality of care (qualitative study nested within a multicentre longitudinal quantitative study). BMJ Open. doi:10.1136/bmjopen-2014-005668.

28. Kendrick, D., O'Brien, C., Christie, N., Coupland, C., Quinn, C., Avis, M., et al. (2011). The impact of injuries study. Multicentre study assessing physical, psychological, social and occupational functioning post injury-a protocol. BMC Public Health, 11(1), 963.

29. Jacobson, R. R. (1995). The post-concussional syndrome: Physiogenesis, psychogenesis and malingering. An integrative model. Journal of Psychosomatic Research, 39(6), 675-693.

30. Lishman, W. A. (1988). Physiogenesis and psychogenesis in the 'post-concussional syndrome'. British Journal of Psychiatry, 153, 460-469.

31. Department for Communities and Local Government. English Indices of Deprivation. (2010). https://www.gov.uk/government/ statistics/english-indices-of-deprivation-2010. Accessed 12/12/ 14.

32. The EuroQol Group. (1992). EuroQol-a new facility for the measurement of health-related quality of life The EuroQol Group. Health Policy, 20(3), 321-328. discussion 329-332.

33. Bjelland, I., Dahl, A. A., Haug, T. T., \& Neckelmann, D. (2002). The validity of the hospital anxiety and depression scale: An updated literature review. Journal of Psychosomatic Research, 52(2), 69-77.

34. Saunders, J. B., Aasland, O. G., Babor, T. F., De La Fuente, J. R., \& Grant, M. (1993). Development of the alcohol use disorders identification test (AUDIT): WHO collaborative project on early detection of persons with harmful alcohol consumption-II. Addiction (Abingdon, England), 88, 791-804.

35. Maisto, S. A., Carey, M. P., Carey, K. B., Gordon, C. M., \& Gleason, J. R. (2000). Use of the AUDIT and the DAST-10 to identify alcohol and drug use disorders among adults with a severe and persistent mental illness. Psychological Assessment, 12(2), 186-192.

36. Tyrer, P., Nur, U., Crawford, M., Karlsen, S., MacLean, C., Rao, B., et al. (2005). The social functioning questionnaire: A rapid and robust measure of perceived functioning. International Journal of Social Psychiatry, 51(3), 265-275.

37. Hawker, G. A., Mian, S., Kendzerska, T., \& French, M. (2011). Measures of adult pain: Visual analog scale for Pain (VAS Pain), Numeric Rating Scale for Pain (NRS Pain), McGill Pain Questionnaire (MPQ), Short-Form McGill Pain Questionnaire (SFMPQ), Chronic Pain Grade Scale (CPGS), Short Form-36 Bodily Pain Scale (SF-36 BPS), and Measure of Intermittent and Constant Osteoarthritis Pain (ICOAP). Arthritis Care \& Research, 63(S11), S240-S252. doi:10.1002/acr.20543.

38. Wilson, R., Derrett, S., Hansen, P., \& Langley, J. (2012). Retrospective evaluation versus population norms for the measurement of baseline health status. Health and Quality of Life Outcomes, 10(68), 1-6. doi:10.1186/1477-7525-10-68.

39. Watson, W. L., Ozanne-Smith, J., \& Richardson, J. (2007). Retrospective baseline measurement of self-reported health status and health-related quality of life versus population norms in the evaluation of post-injury losses. Injury Prevention, 13(1), 45-50. doi:10.1136/ip.2005.010157.

40. Ramos-Goni, J. M., \& Rivero-Arias, O. (2011). eq5d: A command to calculate index values for the EQ-5D quality-of-life instrument. Stata Journal, 11(1), 120-125.

41. Association of the Advancement of Automotive Medicine. (2008). Abbreviated Injury Scale (AIS) 2005-Update 2008 manuals. Barrington: AAAM.
42. Horowitz, M., Wilner, N., \& Alvarez, W. (1979). Impact of event scale: A measure of subjective stress. Psychosomatic Medicine, 41(3), 209-218.

43. Brugha, T., Bebbington, P., Tennant, C., \& Hurry, J. (1985). The List of threatening experiences: A subset of 12 life event categories with considerable long-term contextual threat. Psychological Medicine, 15, 189-194.

44. Harms, L. (2004). After the accident: Survivors' perceptions of recovery following road trauma. Australian Social Work, 57(2), 161-174.

45. Joseph, S., Andrews, B., Williams, R., \& Yule, W. (1992). Crisis support and psychiatric symptomatology in adult survivors of the Jupiter cruise ship disaster. British Journal of Clinical Psychology, 31, 63-73.

46. Joseph, S., Linley, P. A., Andrews, L., Harris, G., Howle, B., Woodward, C., et al. (2005). Assessing positive and negative changes in the aftermath of adversity: Psychometric evaluation of the changes in outlook questionnaire. Psychological Assessment, 17(1), 70-80. doi:10.1037/1040-3590.17.1.70.

47. Walters, S. J., \& Brazier, J. E. (2005). Comparison of the minimally important difference for two health state utility measures: EQ-5D and SF-6D. [journal article]. Quality of Life Research, 14(6), 1523-1532. doi:10.1007/s11136-004-7713-0.

48. Rubin, D. B. (2004). Multiple imputation for nonresponse in surveys. New York: Wiley.

49. StataCorp. (2013). Stata statistical software: Release 13. College Station, TX: StataCorp LP.

50. Polinder, S., van Beeck, E. F., Essink-Bot, M. L., Toet, H., Looman, C. W. N., Mulder, S., et al. (2007). Functional outcome at 2.5, 5, 9, and 24 months after injury in the Netherlands. Journal of Trauma: Injury, Infection and Critical Care, 62(1), 133-141.

51. Overgaard, M., Høyer, C. B., \& Christensen, E. F. (2011). Longterm survival and health-related quality of life 6 to 9 years after trauma. The Journal of Trauma, 71(2), 435-441.

52. Wilson, R., Hansen, P., Langley, J., \& Derrett, S. (2014). A comparison of injured patient and general population valuations of EQ-5D health states for New Zealand. Health and Quality of Life Outcomes, 12(1), 1-7. doi:10.1186/1477-7525-12-21.

53. Kendrick, D., Vinogradova, Y., Coupland, C., Mulvaney, C. A., Christie, N., Lyons, R. A., et al. (2013). Recovery from injury: The UK Burden of injury multicentre longitudinal study. Injury Prevention, 19, 370-381.

54. Meerding, W. J., Looman, C. W. N., Essink-Bot, M.-L., Toet, H., Mulder, S., \& van Beeck, E. F. (2004). Distribution and determinants of health and work status in a comprehensive population of injury patients. Journal of Trauma and Acute Care Surgery, $56(1), 150-161$.

55. Mason, S., Wardrope, J., Turpin, G., \& Rowlands, A. (2002). Outcomes after injury: A comparison of workplace and nonworkplace injury. The Journal of Trauma, 53(1), 98-103.

56. Gabbe, B. J., Simpson, P. M., Cameron, P. A., Ekegren, C. L., Edwards, E. R., Page, R., et al. (2015). Association between perception of fault for the crash and function, return to work and health status 1 year after road traffic injury: A registry-based cohort study. BMJ Open, 5(11), e009907. doi:10.1136/bmjopen2015-009907.

57. Ubel, P. A., Loewenstein, G., \& Jepson, C. (2003). Whose quality of life? A commentary exploring discrepancies between health state evaluations of patients and the general public. Quality of Life Research, 12(6), 599-607.

58. Polinder, S., Haagsma, J. A., Lyons, R. A., Gabbe, B. J., Ameratunga, S., Cryer, C., et al. (2012). Measuring the population burden of fatal and nonfatal injury. Epidemiologic Reviews, 34(1), 17-31. doi:10.1093/epirev/mxr022.

59. Holtslag, H. R., van Beeck, E. F., Lichtveld, R. A., Leenen, L. P. H., Lindeman, E., \& van der Werken, C. (2008). Individual and 
population burdens of major trauma in the Netherlands. Bulletin of the World Health Organization, 86(2), 111-117. doi:10.2471/ BLT.06.033803.

60. Haagsma, J., Polinder, S., van Beeck, E., Mulder, S., \& Bonsel, G. (2009). Alternative approaches to derive disability weights in injuries: Do they make a difference? Quality of Life Research, 18(5), 657-665. doi:10.1007/s11136-009-9484-0.

61. Kanis, J. A., Oden, A., Johnell, O., Jonsson, B., de Laet, C., \& Dawson, A. (2001). The burden of osteoporotic fractures: A method for setting intervention thresholds. Osteoporosis International, 12(5), 417-427.

62. Borgström, F., Sobocki, P., Ström, O., \& Jönsson, B. (2007). The societal burden of osteoporosis in Sweden. Bone, 40(6), 1602-1609. doi:10.1016/j.bone.2007.02.027.
63. Lyons, R. A., Kendrick, D., Towner, E. M., Christie, N., Macey, S., Coupland, C., et al. (2011). Measuring the population burden of injuries-Implications for global and national estimates: A multi-centre prospective UK longitudinal study. PLoS Med, 8(12), e1001140. doi:10.1371/journal.pmed.1001140.

64. Harcombe, H., Langley, J., Davie, G., \& Derrett, S. (2015). Functional status following injury: What recovery pathways do people follow? Injury, 46(7), 1275-1280. doi:10.1016/j.injury. 2015.04.004.

65. National Institiute for Clinical Excellence. (2005). Post-traumatic stress disorder: Management. Clinical Guideline 26. Manchester.

66. National Institute for Health and Care Excellence. (2009). Depression in adults: Recognition and management. Clinical guideline 90. Manchester. 